\title{
A new type of multivalued contraction in partial Hausdorff metric spaces endowed with a graph
}

\author{
Muhammad Usman Ali' ${ }^{1}$ Tayyab Kamran ${ }^{1,2^{*}}$ and Liaqat Ali Khan ${ }^{3}$
}

\section{"Correspondence:}

tayyabkamran@gmail.com

'Department of Mathematics,

School of Natural Sciences, National

University of Sciences and

Technology, H-12, Islamabad,

Pakistan

2Department of Mathematics,

Quaid-i-Azam University, Islamabad, Pakistan

Full list of author information is available at the end of the article

\begin{abstract}
A generalization, namely the $K$-comparison function, of a comparison function is introduced. Using $K$-comparison functions we introduce $K_{G}$-contractive mappings. We obtain a fixed point theorem for such mappings on partial Hausdorff metric spaces endowed with a graph. We also construct examples in support of our results.
\end{abstract}

MSC: $47 \mathrm{H} 10 ; 54 \mathrm{H} 25$

Keywords: $K$-comparison function; $K_{G}$-contractive mapping; partial metric space; partial Hausdorff metric space

\section{Introduction}

Development in metric fixed point theory is based on two things: the first is to modify contraction condition and the second is to modify the structure of a metric space. Matthews [1] introduced the notion of a partial metric space and extended Banach contraction principle in the setting of partial metric space. The work of Matthews [1] has been extended by many authors; see for example [2-17]. Using the notion of a partial metric on a set $X$, Aydi et al. [18] defined a partial Hausdorff metric on the set of closed and bounded subsets of the set $X$. Moreover, they [18] extended Nadler's fixed point theorem in the setting of a partial Hausdorff metric spaces. Jachymaski [19] generalized the Banach fixed point theorem for mappings of a complete metric space endowed with a graph. He introduced the notion of Banach $G$-contractions. Here $G$ stands for a directed graph in a metric space whose vertex set coincides with the metric space. Many authors extended the Banach $G$-contraction in different ways; see, for example, [19-28].

In this paper, we introduce the notions of a $K$-comparison function and a $K_{G}$-contractive mapping. We establish a fixed point theorem for $K_{G}$-contractive mappings, in the setting of partial Hausdorff metric spaces endowed with a graph.

\section{Preliminaries}

In this section we recollect some definitions from partial (Hausdorff) metric spaces and comparison functions. We also present some results from partial (Hausdorff) metric spaces for ready reference. Throughout this paper, $\mathbb{R}^{+}=[0, \infty)$. 
Definition 2.1 [1] Let $X$ be a nonempty set. A mapping $p: X \times X \rightarrow \mathbb{R}^{+}$is a partial metric on $X$, if for all $x, y, z \in X$. We have

(P1) $p(x, x)=p(y, y)=p(x, y)$ if and only if $x=y$;

(P2) $p(x, x) \leq p(x, y)$;

(P3) $p(x, y)=p(y, x)$;

(P4) $p(x, z) \leq p(x, y)+p(y, z)-p(y, y)$.

Remark 2.2 [18] If $p(x, y)=0$, then (P1) and (P2) implies $x=y$ but the converse is not true in general.

Example 2.3 [1] Let $X$ be the set of all closed intervals of real line $\mathbb{R}$, that is, $X=\{[a, b]$ : $a, b \in \mathbb{R}, a \leq b\}$ and define a function $p: X \times X \rightarrow \mathbb{R}^{+}$by $p([a, b],[c, d])=\max \{b, d\}-$ $\min \{a, c\}$, then $(X, p)$ is a partial metric space.

Lemma 2.4 [1] Every metric space is a partial metric space.

Remark 2.5 [1] Every partial metric $p$ on $X$ generates a $T_{0}$ topology $\tau_{p}$ on $X$ with as a base the family of the open balls ( $p$ balls) $\left\{B_{p}(x, \epsilon): x \in X, \epsilon>0\right\}$, where

$$
B_{p}(x, \epsilon)=\{y \in X: p(x, y)<p(x, x)+\epsilon\} .
$$

Definition 2.6 [1] Let $(X, p)$ be a partial metric space. Then:

(a) A sequence $\left\{x_{n}\right\}$ in $(X, p)$ is said to be convergent to a point $x \in X$ with respect to $\tau_{p}$ if and only if $p(x, x)=\lim _{n \rightarrow \infty} p\left(x, x_{n}\right)$.

(b) A sequence $\left\{x_{n}\right\}$ in $X$ will be a Cauchy sequence if and only if $\lim _{n, m \rightarrow \infty} p\left(x_{n}, x_{m}\right)$ exists and is finite.

(c) A partial metric space $(X, p)$ is called a complete partial metric space if every Cauchy sequence $\left\{x_{n}\right\}$ in $X$ converges with respect to $\tau_{p}$ to a point $x \in X$.

Remark 2.7 [1] Let $(X, p)$ be a partial metric space, then the function $d_{p}: X \times X \rightarrow[0, \infty)$ defined by

$$
d_{p}(x, y)=2 p(x, y)-p(x, x)-p(y, y)
$$

is a metric on $X$.

Lemma 2.8 [1] Let $(X, p)$ be a partial metric space, a sequence $\left\{x_{n}\right\}$ in $\left(X, d_{p}\right)$ is said to be convergent to a point $x \in X$ if and only if

$$
p(x, x)=\lim _{n \rightarrow \infty} p\left(x, x_{n}\right)=\lim _{n, m \rightarrow \infty} p\left(x_{n}, x_{m}\right) .
$$

Lemma 2.9 [18] Let $(X, p)$ be a partial metric space. Then:

(a) A sequence $\left\{x_{n}\right\}$ in $X$ is Cauchy with respect to $p$ if and only if it is Cauchy with respect to $d_{p}$.

(b) A partial metric space $(X, p)$ is complete if and only if the metric space $\left(X, d_{p}\right)$ is complete. 
A subset $A$ of a partial metric space $(X, p)$ is a bounded [18], if there exists $x_{0} \in A$ such that $p\left(x_{0}, a\right)<p\left(x_{0}, x_{0}\right)+M$. A subset $A$ of a partial metric space is closed if it is closed with respect to the topology $\tau_{p}$ on $X$. Let $\mathrm{CB}_{p}(X)$ be the family of all nonempty closed and bounded subsets of a partial metric space $(X, p)$. We use the following notions and terminologies [18]. For $A, B \in \mathrm{CB}_{p}(X), p(x, A)=\inf \{p(x, a): a \in A\}, p(A, B)=\inf \{p(x, y)$ : $x \in A, y \in B\}$. The functions $\delta_{p}: \mathrm{CB}_{p}(X) \times \mathrm{CB}_{p}(X) \rightarrow \mathbb{R}^{+}$and $H_{p}: \mathrm{CB}_{p}(X) \times \mathrm{CB}_{p}(X) \rightarrow \mathbb{R}^{+}$ are defined by $\delta_{p}(A, B)=\sup \{p(a, B): a \in A\}$ and $H_{p}(A, B)=\max \left\{\delta_{p}(A, B), \delta_{p}(B, A)\right\}$, respectively.

Remark 2.10 [18] If $d_{p}(x, A)=\inf \left\{d_{p}(x, a): a \in A\right\}$, then it is easy to prove that $p(x, A)=0$ implies that $d_{p}(x, A)=0$.

Lemma 2.11 [18] Let $(X, p)$ be a partial metric space and $A$ be any nonempty subset of $X$, then $a \in \bar{A}$ if and only if $p(a, A)=p(a, a)$.

Lemma 2.12 [18] Let $(X, p)$ be a partial metric space and $A$ be any nonempty subset of $X$. If $A$ is closed in $(X, p)$, then $A$ is closed in $\left(X, d_{p}\right)$.

Proposition 2.13 [18] Let $(X, p)$ be a partial metric space. For $A, B \in \mathrm{CB}_{p}(X)$, the following properties hold:

(1) $H_{p}(A, A) \leq H_{p}(A, B)$;

(2) $H_{p}(A, B)=H_{p}(B, A)$;

(3) $H_{p}(A, C) \leq H_{p}(A, B)+H_{p}(B, C)-\inf _{c \in C} p(c, c)$;

(4) $H_{p}(A, B)=0$ implies that $A=B$.

Lemma 2.14 [18] Let $(X, p)$ be a partial metric space, let $A, B \in \mathrm{CB}_{p}(X)$ and $h>1$. For any $a \in A$, there exists $b \in B$ such that $p(a, b) \leq h H_{p}(A, B)$.

Let $\xi:[0, \infty) \rightarrow[0, \infty)$ be a function. Consider the following conditions:

(i) $\xi$ is an increasing function;

(ii) $\xi(t)<t$ for each $t>0$;

(iii) $\xi(0)=0$;

(iv) $\left\{\xi^{n}(t)\right\}$ converges to 0 for each $t \geq 0$;

(v) $\sum_{n=0}^{\infty} \xi^{n}(t)$ converges for each $t>0$.

The function $\xi$ satisfying (i) and (iv) is said to be a comparison function [29]. The function $\xi$ satisfying (i) and (v) is known as a (c)-comparison function [29]. It is easily seen that (i) and (iv) imply (ii); and (i) and (ii) imply (iii) [29].

Property (A): ([19], Remark 3.1) For any sequence $\left\{x_{n}\right\}_{n \in \mathbb{N}}$ in $X$, if $x_{n} \rightarrow x$ and $\left(x_{n}, x_{n+1}\right) \in$ $E$ for $n \in \mathbb{N}$, then $\left(x_{n}, x\right) \in E$.

\section{Main results}

We begin this section by introducing the notion of a $K$-comparison function.

Definition 3.1 A mapping $\zeta:[0, \infty) \rightarrow[0, \infty)$ is said to be a $K$-comparison if the following conditions hold:

(i) for each $t>0$, we have $\zeta(t)<t$;

(ii) $\zeta(0)=0$. 
Note that any comparison or $(c)$-comparison function is $K$-comparison function but converse is not true in general.

Example 3.2 Let $\zeta:[0, \infty) \rightarrow[0, \infty)$ be a mapping such that

$$
\zeta(t)= \begin{cases}\frac{t}{2} & \text { if } 0 \leq t \leq 2, \\ \sqrt{t} & \text { otherwise }\end{cases}
$$

Thus, $\zeta$ is a $K$-comparison function but neither a comparison nor a $(c)$-comparison function.

We denote the class of $K$-comparison functions by $\mathfrak{K}$. Throughout this section, $(X, p)$ is a partial metric space, $G=(V, E)$ is a directed graph without parallel edges such that $V=X$ and $\triangle=\{(x, x): x \in X\} \subset E$. For basic terminologies of graph theory we refer the reader to the excellent text by Chartrand et al. [30].

Definition 3.3 Let $(X, p)$ be a partial metric space. A mapping $T: X \rightarrow \mathrm{CB}_{p}(X)$ is said to be $K_{G}$-contractive, if there exists $\zeta \in \mathfrak{K}$ with $\sup _{t>0} \frac{\zeta(t)}{t}<1$ such that

(i) for each $(x, y) \in E$ with $x \neq y$, we have

$$
H_{p}(T x, T y) \leq \zeta\left(\max \left\{p(x, y), \frac{p(x, T x)+p(y, T y)}{2}, \frac{p(x, T y)+p(y, T x)}{2}\right\}\right)
$$

(ii) if $s \in T x$ and $t \in T y$ are such that

$$
p(s, t)<p(x, y)
$$

then we have $(s, t) \in E$, whenever $(x, y) \in E$ with $x \neq y$.

Theorem 3.4 Let $(X, p)$ be a complete partial metric space endowed with the graph $G$ and Property (A). Let $T: X \rightarrow \mathrm{CB}_{p}(X)$ be a $K_{G}$-contractive mapping. Assume that there exist $x_{0} \in X$ and $x_{1} \in T x_{0}$ such that $\left(x_{0}, x_{1}\right) \in E$. Then $T$ has a fixed point.

Proof By hypothesis, we have $x_{0} \in X$ and $x_{1} \in T x_{0}$ such that $\left(x_{0}, x_{1}\right) \in E$. If $x_{0}=x_{1}$, then $x_{0}$ is a fixed point. Suppose that $x_{0} \neq x_{1}$. Since $T$ is a $K_{G}$-contractive mapping, from (3.1), we have

$$
\begin{aligned}
H_{p}\left(T x_{0}, T x_{1}\right) & \leq \zeta\left(\max \left\{p\left(x_{0}, x_{1}\right), \frac{p\left(x_{0}, T x_{0}\right)+p\left(x_{1}, T x_{1}\right)}{2}, \frac{p\left(x_{0}, T x_{1}\right)+p\left(x_{1}, T x_{0}\right)}{2}\right\}\right) \\
& <\max \left\{p\left(x_{0}, x_{1}\right), \frac{p\left(x_{0}, T x_{0}\right)+p\left(x_{1}, T x_{1}\right)}{2}, \frac{p\left(x_{0}, T x_{1}\right)+p\left(x_{1}, T x_{0}\right)}{2}\right\} .
\end{aligned}
$$

Then there exists $a_{1} \in(0, l]$, where $l=\sup _{t>0} \frac{\zeta(t)}{t}$, and obviously $a_{1}$ depends on $x_{0}$ and $x_{1}$, such that

$$
\begin{aligned}
& H_{p}\left(T x_{0}, T x_{1}\right) \\
& \quad \leq a_{1} \max \left\{p\left(x_{0}, x_{1}\right), \frac{p\left(x_{0}, T x_{0}\right)+p\left(x_{1}, T x_{1}\right)}{2}, \frac{p\left(x_{0}, T x_{1}\right)+p\left(x_{1}, T x_{0}\right)}{2}\right\} .
\end{aligned}
$$


Since $a_{1}<1$, then $1 / \sqrt{a_{1}}>1$. Thus, by using Lemma 2.14 , we have $x_{2} \in T x_{1}$ such that

$$
p\left(x_{1}, x_{2}\right) \leq \frac{1}{\sqrt{a_{1}}} H_{p}\left(T x_{0}, T x_{1}\right)
$$

From (3.4) and (3.5), we get

$$
\begin{aligned}
p\left(x_{1}, x_{2}\right) & \leq \sqrt{a_{1}} \max \left\{p\left(x_{0}, x_{1}\right), \frac{p\left(x_{0}, x_{1}\right)+p\left(x_{1}, x_{2}\right)}{2}, \frac{p\left(x_{0}, x_{2}\right)+p\left(x_{1}, x_{1}\right)}{2}\right\} \\
& \leq \sqrt{a_{1}} \max \left\{p\left(x_{0}, x_{1}\right), p\left(x_{1}, x_{2}\right)\right\} .
\end{aligned}
$$

If we assume that $\max \left\{p\left(x_{0}, x_{1}\right), p\left(x_{1}, x_{2}\right)\right\}=p\left(x_{1}, x_{2}\right)$, then we get a contradiction to (3.6). Thus, $\max \left\{p\left(x_{0}, x_{1}\right), p\left(x_{1}, x_{2}\right)\right\}=p\left(x_{0}, x_{1}\right)$. From (3.6), we have

$$
p\left(x_{1}, x_{2}\right) \leq \sqrt{a_{1}} p\left(x_{0}, x_{1}\right)<p\left(x_{0}, x_{1}\right) .
$$

From (3.2) and (3.7), we have $\left(x_{1}, x_{2}\right) \in E$. If $x_{1}=x_{2}$, then $x_{1}$ is a fixed point. Suppose that $x_{1} \neq x_{2}$. Again, from (3.1), we have

$$
\begin{aligned}
H_{p}\left(T x_{1}, T x_{2}\right) & \leq \zeta\left(\max \left\{p\left(x_{1}, x_{2}\right), \frac{p\left(x_{1}, T x_{1}\right)+p\left(x_{2}, T x_{2}\right)}{2}, \frac{p\left(x_{1}, T x_{2}\right)+p\left(x_{2}, T x_{1}\right)}{2}\right\}\right) \\
& <\max \left\{p\left(x_{1}, x_{2}\right), \frac{p\left(x_{1}, T x_{1}\right)+p\left(x_{2}, T x_{2}\right)}{2}, \frac{p\left(x_{1}, T x_{2}\right)+p\left(x_{2}, T x_{1}\right)}{2}\right\} .
\end{aligned}
$$

Then there exists $a_{2} \in(0, l]$, and obviously $a_{2}$ depends on $x_{1}$ and $x_{2}$, such that

$$
\begin{aligned}
& H_{p}\left(T x_{1}, T x_{2}\right) \\
& \quad \leq a_{2} \max \left\{p\left(x_{1}, x_{2}\right), \frac{p\left(x_{1}, T x_{1}\right)+p\left(x_{2}, T x_{2}\right)}{2}, \frac{p\left(x_{1}, T x_{2}\right)+p\left(x_{2}, T x_{1}\right)}{2}\right\} .
\end{aligned}
$$

Since $a_{2}<1,1 / \sqrt{a_{2}}>1$. Again by using Lemma 2.14, we have $x_{3} \in T x_{2}$ such that

$$
p\left(x_{2}, x_{3}\right) \leq \frac{1}{\sqrt{a_{2}}} H_{p}\left(T x_{1}, T x_{2}\right)
$$

From (3.8) and (3.9), we get

$$
\begin{aligned}
p\left(x_{2}, x_{3}\right) & \leq \sqrt{a_{1}} \max \left\{p\left(x_{1}, x_{2}\right), \frac{p\left(x_{1}, x_{2}\right)+p\left(x_{2}, x_{3}\right)}{2}, \frac{p\left(x_{1}, x_{3}\right)+p\left(x_{2}, x_{2}\right)}{2}\right\} \\
& \leq \sqrt{a_{1}} \max \left\{p\left(x_{1}, x_{2}\right), p\left(x_{2}, x_{3}\right)\right\} .
\end{aligned}
$$

If we assume that $\max \left\{p\left(x_{1}, x_{2}\right), p\left(x_{2}, x_{3}\right)\right\}=p\left(x_{2}, x_{3}\right)$, then we get a contradiction to (3.10). Thus, $\max \left\{p\left(x_{1}, x_{2}\right), p\left(x_{2}, x_{3}\right)\right\}=p\left(x_{1}, x_{2}\right)$. From (3.10), we have

$$
p\left(x_{2}, x_{3}\right) \leq \sqrt{a_{2}} p\left(x_{1}, x_{2}\right)<p\left(x_{1}, x_{2}\right) .
$$

Also, we have

$$
p\left(x_{2}, x_{3}\right) \leq \sqrt{a_{2}} p\left(x_{1}, x_{2}\right) \leq \sqrt{a_{2}} \sqrt{a_{1}} p\left(x_{0}, x_{1}\right) .
$$


Continuing the same way we get sequences $\left\{a_{n}\right\} \subset(0, l]$ and $\left\{x_{n}\right\} \subset X$ such that $x_{n-1} \in T x_{n}$, $x_{n-1} \neq x_{n}$, and $\left(x_{n-1}, x_{n}\right) \in E$, with

$$
p\left(x_{n}, x_{n+1}\right) \leq \sqrt{a_{n}} \sqrt{a_{n-1}} \cdots \sqrt{a_{1}} p\left(x_{0}, x_{1}\right) \quad \text { for each } n \in \mathbb{N} .
$$

Let $n, m \in \mathbb{N}$, by using the triangular inequality, we have

$$
\begin{aligned}
p\left(x_{n}, x_{n+m}\right) \leq & p\left(x_{n}, x_{n+1}\right)+p\left(x_{n+1}, x_{n+2}\right)+\cdots+p\left(x_{n+m-1}, x_{n+m}\right)-\sum_{i=n+1}^{n+m-1} p\left(x_{i}, x_{i}\right) \\
\leq & p\left(x_{n}, x_{n+1}\right)+p\left(x_{n+1}, x_{n+2}\right)+\cdots+p\left(x_{n+m-1}, x_{n+m}\right) \\
\leq & \sqrt{a_{n}} \sqrt{a_{n-1}} \cdots \sqrt{a_{1}} p\left(x_{0}, x_{1}\right)+\sqrt{a_{n+1}} \sqrt{a_{n}} \cdots \sqrt{a_{1}} p\left(x_{0}, x_{1}\right) \\
& +\cdots+\sqrt{a_{n+m-1}} \sqrt{a_{n+m-2}} \cdots \sqrt{a_{1}} p\left(x_{0}, x_{1}\right) .
\end{aligned}
$$

Let $b=\sup \left\{\sqrt{a_{i}}: i \in \mathbb{N}\right\}$, clearly, $b<1$. Then from (3.12), we get

$$
\begin{aligned}
p\left(x_{n}, x_{n+m}\right) \leq & \sqrt{a_{n}} \sqrt{a_{n-1}} \cdots \sqrt{a_{1}} p\left(x_{0}, x_{1}\right)+\sqrt{a_{n+1}} \sqrt{a_{n}} \cdots \sqrt{a_{1}} p\left(x_{0}, x_{1}\right) \\
& +\cdots+\sqrt{a_{n+m-1}} \sqrt{a_{n+m-2}} \cdots \sqrt{a_{1}} p\left(x_{0}, x_{1}\right) \\
\leq & {\left[b^{n}+b^{n+1}+\cdots+b^{n+m-1}\right] p\left(x_{0}, x_{1}\right) } \\
< & \frac{b^{n}}{1-b} p\left(x_{0}, x_{1}\right) .
\end{aligned}
$$

Consequently, we have

$$
d_{p}\left(x_{n}, x_{n+m}\right) \leq 2 p\left(x_{n}, x_{n+m}\right)<\frac{2 b^{n}}{1-b} p\left(x_{0}, x_{1}\right) .
$$

Thus, we conclude that $\left\{x_{n}\right\}$ is a Cauchy sequence in $\left(X, d_{p}\right)$. Since $(X, p)$ is a complete partial metric space, by Lemma 2.9(b), $\left(X, d_{p}\right)$ is a complete metric space. Then there exists $x^{*} \in X$ such that $x_{n} \rightarrow x^{*} \in X$ with respect to $d_{p}$, as $n \rightarrow \infty$. By Lemma 2.8, we have

$$
p\left(x^{*}, x^{*}\right)=\lim _{n \rightarrow \infty} p\left(x_{n}, x^{*}\right)=\lim _{n \rightarrow \infty} p\left(x_{n}, x_{n+m}\right)=0
$$

By Property (A), we have $\left(x_{n}, x^{*}\right) \in E$ for each $n \in \mathbb{N}$. Now, we claim that $p\left(x^{*}, T x^{*}\right)=0$. On the contrary suppose that $p\left(x^{*}, T x^{*}\right)>0$. By using the triangular inequality and (3.1), we have

$$
\begin{aligned}
p\left(x^{*}, T x^{*}\right) \leq & p\left(x^{*}, x_{n+1}\right)+p\left(x_{n+1}, T x^{*}\right)-p\left(x_{n+1}, x_{n+1}\right) \\
\leq & p\left(x^{*}, x_{n+1}\right)+H_{p}\left(T x_{n}, T x^{*}\right) \\
\leq & p\left(x^{*}, x_{n+1}\right)+\zeta\left(\operatorname { m a x } \left\{p\left(x_{n}, x^{*}\right), \frac{p\left(x_{n}, T x_{n}\right)+p\left(x^{*}, T x^{*}\right)}{2},\right.\right. \\
& \left.\left.\frac{p\left(x_{n}, T x^{*}\right)+p\left(x^{*}, T x_{n}\right)}{2}\right\}\right) \\
< & p\left(x^{*}, x_{n+1}\right)+\max \left\{p\left(x_{n}, x^{*}\right), \frac{p\left(x_{n}, T x_{n}\right)+p\left(x^{*}, T x^{*}\right)}{2},\right.
\end{aligned}
$$




$$
\begin{aligned}
& \left.\frac{p\left(x_{n}, T x^{*}\right)+p\left(x^{*}, T x_{n}\right)}{2}\right\} \\
\leq & p\left(x^{*}, x_{n+1}\right)+\max \left\{p\left(x_{n}, x^{*}\right), \frac{p\left(x_{n}, x_{n+1}\right)+p\left(x^{*}, T x^{*}\right)}{2},\right. \\
& \left.\frac{p\left(x_{n}, x^{*}\right)+p\left(x^{*}, T x^{*}\right)-p\left(x^{*}, x^{*}\right)+p\left(x^{*}, x_{n+1}\right)}{2}\right\} .
\end{aligned}
$$

Letting $n \rightarrow \infty$ in the above inequality,

$$
p\left(x^{*}, T x^{*}\right) \leq \frac{p\left(x^{*}, T x^{*}\right)}{2},
$$

but this is impossible for $p\left(x^{*}, T x^{*}\right)>0$. Thus, $p\left(x^{*}, T x^{*}\right)=0$. Therefore, we have

$$
p\left(x^{*}, T x^{*}\right)=0=p\left(x^{*}, x^{*}\right) .
$$

This implies that $x^{*} \in T x^{*}$.

Example 3.5 Let $X=\mathbb{N} \cup\{0\}$ endowed with the partial metric $p(x, y)=\max \{x, y\}$ and a graph $G=(V, E)$ be defined as $V=X$ and $E=\{(x, y): x, y \in\{0,2,4,6,8,10,12,14,16\}\} \cup$ $\{(x, x): x \in \mathbb{N}\}$. Let $T: X \rightarrow \mathrm{CB}_{p}(X)$ be defined by

$$
T x= \begin{cases}\{0\} & \text { if } x \in\{0,2,6,10,12,14\} \\ \{0,2\} & \text { if } x=4, \\ \{0,4\} & \text { if } x=8 \\ \{0,8\} & \text { if } x=16 \\ \{x+1, x+2\} & \text { otherwise }\end{cases}
$$

and $\zeta:[0, \infty) \rightarrow[0, \infty)$ by

$$
\zeta(t)= \begin{cases}\frac{t}{2} & \text { if } 0 \leq t \leq 4, \\ \frac{2 t}{3} & \text { if } 4<t \leq 8, \\ \frac{t}{2} & \text { if } t>8 .\end{cases}
$$

To see that (3.1) holds it is sufficient to consider the following cases:

(i) If $(x, y) \in E$ with $x \neq y \in\{0,2,6,10,12,14\}$, then (3.1) trivially holds.

(ii) If $(x, y) \in E$ with $x \in\{0,2,6,10,12,14\}$ and $y=4$, then

$$
H_{p}(T x, T y)=2 \leq \zeta\left(M_{p}(x, y)\right)
$$

(iii) If $(x, y) \in E$ with $x \in\{0,2,6,10,12,14\}$ and $y=8$, then

$$
H_{p}(T x, T y)=4 \leq \zeta\left(M_{p}(x, y)\right)
$$

(iv) If $(x, y) \in E$ with $x \in\{0,2,6,10,12,14\}$ and $y=16$, then

$$
H_{p}(T x, T y)=8 \leq \zeta\left(M_{p}(x, y)\right)
$$


(v) If $(x, y) \in E$ with $x=4$ and $y=8$, then

$$
H_{p}(T x, T y)=4 \leq \zeta\left(M_{p}(x, y)\right)
$$

(vi) If $(x, y) \in E$ with $x=4$ and $y=16$, then

$$
H_{p}(T x, T y)=8 \leq \zeta\left(M_{p}(x, y)\right)
$$

(vii) If $(x, y) \in E$ with $x=8$ and $y=16$, then

$$
H_{p}(T x, T y)=8 \leq \zeta\left(M_{p}(x, y)\right)
$$

where $M_{p}(x, y)=\max \left\{p(x, y), \frac{p(x, T x)+p(y, T y)}{2}, \frac{p(x, T y)+p(x, T y)}{2}\right\}$. Thus, (3.1) holds. Further it can be observed that for $(x, y) \in E$ with $x \neq y$, if $s \in T x$ and $t \in T y$ are such that $p(s, t)<p(x, y)$, then we have $(s, t) \in E$. For $x_{0}=8$, we have $x_{1}=4 \in T x_{0}$ such that $(8,4) \in E$. Moreover, Property (A) holds. Therefore, Theorem 3.4 guarantees the existence of a fixed point of $T$.

Example 3.6 Let $X=[0, \infty) \times[0, \infty)$ be endowed with the partial metric $p(x, y)=$ $p\left(\left(x_{1}, x_{2}\right),\left(y_{1}, y_{2}\right)\right)=\max \left\{x_{1}, y_{1}\right\}+\max \left\{x_{2}, y_{2}\right\}$ and a graph $G=(V, E)$ be defined as $V=X$ and $E=\left\{(r, s): r=\left(r_{1}, 0\right), s=\left(s_{1}, 0\right)\right.$ with $\left.r_{1}, s_{1} \geq 0\right\} \cup\{(x, x): x \in X\}$. Let $T: X \rightarrow \mathrm{CB}_{p}(X)$ be defined by

$$
T(b, a)=\{(0,0),(b / 2, a)\} \quad \text { for each }(b, a) \in X
$$

and $\zeta:[0, \infty) \rightarrow[0, \infty)$ be defined as

$$
\zeta(t)= \begin{cases}\frac{2 t}{3} & \text { if } 0 \leq t \leq 10 \\ \frac{t}{2} & \text { otherwise }\end{cases}
$$

To see that (3.1) holds, we consider the following cases:

(i) If $((u, 0),(v, 0)) \in E$ with $0 \leq u<v$, then

$$
H_{p}(T(u, 0), T(v, 0))=\frac{v}{2} \leq \zeta\left(M_{p}(x, y)\right) .
$$

(ii) If $((u, 0),(v, 0)) \in E$ with $0 \leq v<u$, then

$$
H_{p}(T(u, 0), T(v, 0))=\frac{u}{2} \leq \zeta\left(M_{p}(x, y)\right),
$$

where $M_{p}(x, y)=\max \left\{p(x, y), \frac{p(x, T x)+p(y, T y)}{2}, \frac{p(x, T y)+p(x, T y)}{2}\right\}$. Thus, (3.1) holds. Further it can be observed that for $(x, y) \in E$ with $x \neq y$, if $s \in T x$ and $t \in T y$ are such that $p(s, t)<p(x, y)$, then we have $(s, t) \in E$. For $x_{0}=(1,0)$, we have $x_{1}=(0.5,0) \in T x_{0}$ such that $((1,0),(0.5,0)) \in E$. Moreover, Property (A) holds. Therefore, Theorem 3.4 guarantees the existence of a fixed point of $T$.

Note that the following results are direct consequences of our result. 
Corollary 3.7 Let $(X, p)$ be a complete partial metric space endowed with a graph $G$ and Property (A). Let $T: X \rightarrow \mathrm{CB}_{p}(X)$ be a mapping such that

(i) for each $(x, y) \in E$ with $x \neq y$, we have

$$
H_{p}(T x, T y) \leq \phi\left(M_{p}(x, y)\right) M_{p}(x, y)
$$

where $M_{p}(x, y)=\max \left\{p(x, y), \frac{p(x, T x)+p(y, T y)}{2}, \frac{p(x, T y)+p(x, T y)}{2}\right\}$, and $\phi:[0, \infty) \rightarrow[0,1)$ is such that $\lim \sup _{t \rightarrow r^{+}} \phi(t)<1$ for each $r \in[0, \infty)$;

(ii) if $s \in T x$ and $t \in T y$ are such that $p(s, t)<p(x, y)$, then we have $(s, t) \in E$, whenever $(x, y) \in E$ with $x \neq y$.

Further, assume that there exist $x_{0} \in X$ and $x_{1} \in T x_{0}$ such that $\left(x_{0}, x_{1}\right) \in E$. Then $T$ has a fixed point.

This result can be obtained from Theorem 3.4, by considering $\zeta(t)=\phi(t) t$ for each $t \geq 0$.

Corollary 3.8 Let $(X, d)$ be a complete metric space endowed with a graph $G$ and Property (A). Let $T: X \rightarrow \mathrm{CB}(X)$ be a mapping such that

(i) for each $(x, y) \in E$ with $x \neq y$, we have

$$
H(T x, T y) \leq \zeta\left(\max \left\{d(x, y), \frac{d(x, T x)+d(y, T y)}{2}, \frac{d(x, T y)+d(x, T y)}{2}\right\}\right),
$$

where $\zeta$ is a $K$-comparison function with $\sup _{t>0} \frac{\zeta(t)}{t}<1$;

(ii) if $s \in T x$ and $t \in T y$ are such that $d(s, t)<d(x, y)$, then we have $(s, t) \in E$, whenever $(x, y) \in E$ with $x \neq y$.

Further, assume that there exist $x_{0} \in X$ and $x_{1} \in T x_{0}$ such that $\left(x_{0}, x_{1}\right) \in E$. Then $T$ has a fixed point.

Corollary 3.9 Let $(X, p)$ be a complete partial metric space endowed with a graph $G$ and Property (A). Let $T: X \rightarrow \mathrm{CB}_{p}(X)$ be a mapping such that

(i) for each $(x, y) \in E$ with $x \neq y$, we have

$$
H_{p}(T x, T y) \leq \zeta\left(\max \left\{p(x, y), \frac{p(x, T x)+p(y, T y)}{2}, \frac{p(x, T y)+p(x, T y)}{2}\right\}\right),
$$

where $\zeta$ is comparison function with $\sup _{t>0} \frac{\zeta(t)}{t}<1$;

(ii) if $s \in T x$ and $t \in T y$ are such that $p(s, t)<p(x, y)$, then we have $(s, t) \in E$, whenever $(x, y) \in E$ with $x \neq y$.

Further, assume that there exist $x_{0} \in X$ and $x_{1} \in T x_{0}$ such that $\left(x_{0}, x_{1}\right) \in E$. Then $T$ has a fixed point.

Corollary 3.10 Let $(X, p)$ be a complete partial metric space endowed with a graph $G$ and Property (A). Let $T: X \rightarrow \mathrm{CB}_{p}(X)$ be a mapping such that

(i) for each $(x, y) \in E$ with $x \neq y$, we have

$$
H_{p}(T x, T y) \leq \zeta\left(\max \left\{p(x, y), \frac{p(x, T x)+p(y, T y)}{2}, \frac{p(x, T y)+p(x, T y)}{2}\right\}\right),
$$

where $\zeta$ is a (c)-comparison function with $\sup _{t>0} \frac{\zeta(t)}{t}<1$; 
(ii) if $s \in T x$ and $t \in T y$ are such that $p(s, t)<p(x, y)$, then we have $(s, t) \in E$, whenever $(x, y) \in E$ with $x \neq y$.

Further, assume that there exist $x_{0} \in X$ and $x_{1} \in T x_{0}$ such that $\left(x_{0}, x_{1}\right) \in E$. Then $T$ has a fixed point.

Corollary 3.11 Let $(X, p)$ be a complete partial metric space endowed with a graph $G$ and Property (A). Let $T: X \rightarrow \mathrm{CB}_{p}(X)$ be a mapping such that

(i) for each $(x, y) \in E$ with $x \neq y$, we have

$$
H_{p}(T x, T y) \leq a \max \left\{p(x, y), \frac{p(x, T x)+p(y, T y)}{2}, \frac{p(x, T y)+p(x, T y)}{2}\right\}
$$

where $a \in[0,1)$;

(ii) if $s \in T x$ and $t \in$ Ty are such that $p(s, t)<p(x, y)$, then we have $(s, t) \in E$, whenever $(x, y) \in E$ with $x \neq y$.

Further, assume that there exist $x_{0} \in X$ and $x_{1} \in T x_{0}$ such that $\left(x_{0}, x_{1}\right) \in E$. Then $T$ has a fixed point.

\section{Competing interests}

The authors declare that they have no competing interests.

\section{Authors' contributions}

All authors contributed equally to the writing of this paper. All authors read and approved the final manuscript.

\section{Author details}

'Department of Mathematics, School of Natural Sciences, National University of Sciences and Technology, $\mathrm{H}-12$, Islamabad, Pakistan. ${ }^{2}$ Department of Mathematics, Quaid-i-Azam University, Islamabad, Pakistan. ${ }^{3}$ Department of Mathematics, Faculty of Science, King Abdulaziz University, Jeddah, Saudi Arabia.

\section{Acknowledgements}

The authors are grateful to the reviewers for their valuable suggestions. One of the authors (LA Khan) wishes to thank King Abdulaziz City of Science and Technology for their financial support under the National Science, Technology and Innovation Plan, Project ID 14-MAT1272-03 and also the Deanship of Scientific Research, King Abdulaziz University, Jeddah, for their technical support.

Received: 26 February 2015 Accepted: 3 June 2015 Published online: 18 June 2015

\section{References}

1. Matthews, SG: Partial metric topology. In: Proc. 8th Summer Conference on General Topology and Applications. Ann. New York Acad. Sci., vol. 728, pp. 183-197 (1994)

2. Altun, I, Simsek, H: Some fixed point theorems on dualistic partial metric spaces. J. Adv. Math. Stud. 1, 1-8 (2008)

3. Altun, I, Sola, F, Simsek, H: Generalized contractions on partial metric spaces. Topol. Appl. 157(18), 2778-2785 (2010)

4. Altun, I, Erduran, A: Fixed point theorems for monotone mappings on partial metric spaces. Fixed Point Theory Appl. 2011, Article ID 508730 (2011)

5. Jleli, M, Samet, B, Vetro, C: Fixed point theory in partial metric spaces via $\phi$-fixed point's concept in metric spaces. J. Inequal. Appl. 2014, 426 (2014)

6. Chen, C, Karapinar, E: Fixed point results for $\alpha$-Meir-Keeler contraction on partial Hausdorff metric spaces. J. Inequal. Appl. 2013, 410 (2013)

7. Ciric, L, Samet, B, Aydi, H, Vetro, C: Common fixed points of generalized contractions on partial metric spaces and an application. Appl. Math. Comput. 218, 2398-2406 (2011)

8. Haghi, RH, Rezapour, S, Shahzad, N: Be careful on partial metric fixed point results. Topol. Appl. 160, 450-454 (2013)

9. Kumam, P, Vetro, C, Vetro, F: Fixed points for weak $\alpha-\psi$-contractions in partial metric spaces. Abstr. Appl. Anal. 2013 Article ID 986028 (2013). doi:10.1155/2013/986028

10. Nashine, HK, Kadelburg, Z: Cyclic contractions and fixed point results via control functions on partial metric spaces. Int. J. Anal. 2013, Article ID 726387 (2013)

11. Kadelburg, Z, Nashine, HK, Radenovic, S: Fixed point results under various contractive conditions in partial metric spaces. Rev. R. Acad. Cienc. Exactas Fís. Nat., Ser. A Mat. 107, 241-256 (2013)

12. Shukla, S, Radenovic, S, Vetro, C: Set-valued Hardy-Rogers type contraction in 0-complete partial metric spaces. Int. J. Math. Math. Sci. 2014, Article ID 652925 (2014)

13. Ilic, D, Pavlovic, V, Rakocevic, V: Some new extensions of Banach's contraction principle to partial metric space. Appl. Math. Lett. 24, 1326-1330 (2011)

14. Karapinar, E, Rakocevic, V: On cyclic generalized weakly C-contractions on partial metric spaces. Abstr. Appl. Anal. 2013, Article ID 831491 (2013) 
15. Roldan, A, Martinez-Moreno, J, Roldan, C, Karapinar, E: Multidimensional fixed point theorems in partially ordered complete partial metric spaces under $(\psi, \varphi)$-contractivity conditions. Abstr. Appl. Anal. 2013, Article ID 634371 (2013)

16. Karapinar, E, Romaguera, S: Nonunique fixed point theorems in partial metric spaces. Filomat 27(7), 1305-1314 (2013)

17. Karapinar, E, Shatanawi, W, Tas, K: Fixed point theorem on partial metric spaces involving rational expressions. Miskolc Math. Notes 14, 135-142 (2013)

18. Aydi, H, Abbas, M, Vetro, C: Partial Hausdorff metric and Nadler's fixed point theorem on partial metric spaces. Topol. Appl. 159, 3234-3242 (2012)

19. Jachymski, J: The contraction principle for mappings on a metric space with a graph. Proc. Am. Math. Soc. 136(4), 1359-1373 (2008)

20. Vetro, C, Vetro, F: Metric or partial metric spaces endowed with a finite number of graphs: a tool to obtain fixed point results. Topol. Appl. 164, 125-137 (2014)

21. Tiammee, J, Suantai, S: Coincidence point theorems for graph-preserving multi-valued mappings. Fixed Point Theory Appl. 2014, 70 (2014). doi:10.1186/1687-1812-2014-70

22. Samreen, M, Kamran, T: Fixed point theorems for integral G-contractions. Fixed Point Theory Appl. 2013, 149 (2013). doi:10.1186/1687-1812-2013-149

23. Kamran, T, Samreen, M, Shahzad, N: Probabilistic G-contractions. Fixed Point Theory Appl. 2013, 223 (2013). doi:10.1186/1687-1812-2013-223

24. Samreen, M, Kamran, T, Shahzad, N: Some fixed point theorems in b-metric space endowed with a graph. Abstr. Appl. Anal. 2013, Article ID 967132 (2013). doi:10.1155/2013/967132

25. Bojor, F: Fixed point of $\varphi$-contraction in metric spaces endowed with a graph. An. Univ. Craiova, Math. Comput. Sci. Ser. 37(4), 85-92 (2010)

26. Bojor, F: Fixed point theorems for Reich type contractions on metric spaces with a graph. Nonlinear Anal. 75, 3895-3901 (2012)

27. Nicolae, A, O'Regan, D, Petrusel, A: Fixed point theorems for single-valued and multivalued generalized contractions in metric spaces endowed with a graph. Georgian Math. J. 18, 307-327 (2011)

28. Aleomraninejad, SMA, Rezapour, S, Shahzad, N: Some fixed point results on a metric space with a graph. Topol. Appl. $159,659-663(2012)$

29. Berinde, V: Iterative Approximation of Fixed Points. Lecture Notes in Mathematics, vol. 1912. Springer, Berlin (2002)

30. Chartrand, G, Lesniak, L, Zhang, P: Graphs and Digraphs, 5th edn. CRC Press, Boca Raton (2011)

\section{Submit your manuscript to a SpringerOpen ${ }^{\circ}$ journal and benefit from:}

- Convenient online submission

Rigorous peer review

- Immediate publication on acceptance

- Open access: articles freely available online

- High visibility within the field

- Retaining the copyright to your article 